\title{
Methadone for cancer-related neuropathic pain: A review of the literature
}

\author{
Rosemarie Mannino, MD \\ Patrick Coyne, MSN, APRN \\ Craig Swainey, MD \\ Lea Ann Hansen, PharmD \\ Laurie Lyckholm, MD
}

\section{ABSTRACT}

Neuropathic pain is commonly seen in cancerpatients, either as a direct result of the malignancy or as a consequence of the treatment rendered. In recent years, methadone has been utilized in the treatment of neuropathic pain because of its additional mechanism of action as an NMDA-receptor antagonist. In this paper we discuss the etiology of neuropathic pain in cancer patients, unique properties of methadone, and prior studies on methadone in this patient population. While methadone has been established as a cheap and effective agent in treating cancer pain, specific studies are needed comparing methadone to other opioids in the management of cancer-related neuropathic pain.

Key words: neuropathic pain, NMDA receptors, methadone, morphine

\section{INTRODUCTION}

Pain and symptom management are an integral part of cancer management. ${ }^{1,2}$ Neuropathic pain is commonly seen in cancer as a result of either the treatment or the cancer itself. Because of its mechanism of action, methadone is thought by many pain and palliative medicine specialists to be more effective than other opioids in the treatment of neuropathic pain. No specific agent has been identified as the preferred or clearly superior treatment of neuropathic pain, but morphine remains the gold standard for the treatment of cancer pain. A first-line agent should be identified in order to standardize care, and methadone may be a candidate for this distinction. In this article, the causes of neuropathic pain in cancer are reviewed, as well as the literature regarding the use of methadone for neuropathic pain in cancer patients.

\section{NEUROPATHIC PAIN IN CANCER}

\section{Clinical presentation}

Persons with cancer often experience several different types of pain simultaneously, making neuropathic pain difficult to distinguish from somatic and visceral pain. Various malignant processes-for example, vertebral invasion with nerve compression-may present as both somatic and neuropathic pain.

Neuropathic pain can be defined as pain related to abnormal somatosensory processing in either the peripheral or central nervous system. ${ }^{3}$ It may come to exist independently of any initial injury or damage, resulting in a state of persistent pain, ${ }^{4}$ and it can occur at any time during the person's life. In an international survey of 1,095 consecutive cancer patients with severe pain, 40 percent reported a neuropathic component. ${ }^{5}$

Descriptions of neuropathic pain include burning, electric shock, tingling, pricking, itching, cold, aching, numbness, tenderness, pulling, tugging, penetrating, punishing, miserable, and nagging, and the sensations can be associated with neurologic deficits. ${ }^{6,7}$ Patients with neuropathic pain may complain of spontaneous and/or evoked pain. Spontaneous pain, due to sudden, unprovoked firing of axons or dorsal horn neurons, can present as paroxysmal lancinating pain, as constant burning pain, or as a cramping or aching sensation. Evoked pain, caused by damage or alterations to peripheral and central sensory neurons, can present as hyperalgesia (lowered threshold to painful stimuli), allodynia (pain from normally innocuous stimuli, such as light touch), and hyperpathia (increased pain from a normally painful stimulus). ${ }^{4}$ It can be elusive and resistant to many types of analgesics, making it a challenge to treat. ${ }^{8,9}$ 


\section{Causes}

The etiology of neuropathic pain in cancer patients can be a direct result of the malignant disease (compression of a nerve or nerve plexus) or a consequence of treatments such as radiation, surgery, and/or chemotherapy. ${ }^{10,11}$ Radiation-induced plexopathies are most often described as occurring in the brachial or lumbosacral plexus. They include three distinct clinical syndromes: reversible or transient plexopathy; classic delayed, progressive radiation injury with fibrosis; and acute ischemic plexopathy. Transient brachial plexopathy occurs during or within a few months of finishing radiation treatment; it results when an external beam's field has included the brachial plexus, and it usually resolves with time. Most often this occurs in women with early breast cancer who are receiving radiation after conservative surgical treatment. Symptoms include numbness in the thumb and first finger of the affected side and weakness in the shoulder and biceps muscles. ${ }^{12}$

The pathogenesis of radiation-induced plexopathy is unknown and symptoms may resolve spontaneously within weeks or months. Late delayed brachial plexopathy occurs months to years following axillary or supraclavicular radiation. Observation-based evidence suggests that damage stems primarily from vasculitis resulting in sclerotic occlusion of small supplying vessels, or demyelination and fibrosis within and surrounding nerves in the radiation field. Paresthesias, hypesthesias, weakness, and impaired reflexes may occur. ${ }^{12}$

Chronic post-thoracotomy pain syndrome occurs in 44 to 67 percent of patients after thoracotomy, most commonly from recurrent or persistent tumor in the distribution of the thoracotomy. It is defined as pain persisting along the thoracotomy scar longer than two months postoperatively. It usually involves moderate or severe pain in the distribution of one or more intercostal nerves, and the duration of pain appears to be longer in patients with malignancy. The most severe pain in the syndrome, occurring in approximately 3 percent of patients, appears to be due to intercostal neuralgia. The exact mechanism is unclear. ${ }^{13}$

Postmastectomy pain syndrome (PMPS) is a chronic pain condition that was first reported in the 1970s. It is typically neuropathic in nature and can occur following surgery on the breast. PMPS is described as a dull, burning, and aching sensation in the anterior chest, arm, and axilla, exacerbated by movement of the shoulder girdle. The etiology of PMPS is unclear, but theories have been postulated implicating dissection of the intercostobrachial nerve, intraoperative damage to axillary nerve pathways, and/or pain caused by neuroma. ${ }^{14}$

Phantom pain originates from a missing body part (such as a limb or breast) and may exacerbate already disabling conditions, especially in patients with cancer.
Phantom limb pain is reported to occur in as many as 66 percent of patients within the first six months after amputation. In 5 to 10 percent of patients the pain is severe, persistent, and often resistant to conventional therapy with drugs. ${ }^{15}$ Phantom breast pain after mastectomy, which appears to be related to preexisting preoperative pain, can occur in 15 to 30 percent of patients. ${ }^{16}$ There is postulation that transmission of noxious afferent input to the spinal cord from a peripheral injury causes a central neural sensitization, amplifying subsequent input. ${ }^{17,18}$

Chemotherapy-induced peripheral neuropathy has been a significant dose-limiting toxicity, as detailed in a 1999 review by Windebank. ${ }^{19}$ In general, there is a predisposition to neuropathy in patients with prior nerve damage from conditions such as diabetes, heavy alcohol use, or inherited neuropathy. ${ }^{20}$ Classes of agents causing neuropathy include platinum-containing compounds (cisplatin and oxaliplatin), taxanes (paclitaxel and docetaxel), and the vinca alkaloids (vincristine and vinblastine). ${ }^{16}$

With cisplatin, DNA synthesis is impaired as a result of platinum binding to DNA, thereby producing inter- and intrastrand crosslinks. ${ }^{21}$ The neurotoxicity of cisplatin and oxaliplatin manifests as pure sensory involvement, is related to cumulative dosing, and can progress for weeks despite discontinuation of the drug. ${ }^{22}$ Cisplatin is postulated to cause neuronal apoptosis by an unknown mechanism. Oxaliplatin appears to interfere with neural excitability and axonal ion conductance, resulting in neurotoxicity. ${ }^{21}$

The taxanes and vinca alkaloids interfere with microtubule-based axonal transport, thereby causing axonal injury that leads mainly to sensory loss. Paresthesias of the hands and feet are frequently the initial manifestation of neuropathy from these compounds. Unfortunately, these paresthesias can interfere with activities of daily living such as buttoning one's shirt or using a car's gas and brake pedals. The neuropathies associated with these agents tend to resolve in the months following their discontinuation, though not in all cases. Chemotherapyinduced central neurotoxicity may also be caused by methotrexate, cytarabine, and ifosfamide. Acute aseptic meningitis and delayed neurotoxicity including cognitive impairment, aphasia, progressive dementia, and hemiparesis have been described. Risk factors include higher doses of the agents, frequent administration, and radiation preceding methotrexate dosing. ${ }^{21}$

\section{MANAGING NEUROPATHIC PAIN}

\section{Opioids}

Opioids are considered a cornerstone in the management of neuropathic pain. ${ }^{22}$ Two studies by Watson and colleagues $^{23,24}$ addressed this issue in randomized, double-blinded trials using controlled-release oxycodone. 
One trial enlisted patients with postherpetic neuralgia, and the subsequent trial involved patients with painful diabetic neuropathy. Both trials concluded that controlled-release oxycodone is effective in treating neuropathic pain and improving quality of life. The latter study produced a 67.5 percent decrease in VAS pain scores from baseline to the last week of treatment, as compared to 28 percent in the active placebo group treated with benztropine.

Similarly, a multicenter, double-blind, randomized control trial of 159 patients using controlled-release oxycodone in patients with diabetic neuropathy also concluded that the opioid was effective. Of note, 44 of the patients withdrew from the study: 11 for inadequate pain control in the placebo group; one for the same reason in the oxycodone group; and 11 due to adverse events (nausea, constipation, dizziness, headache), seven of whom were in the oxycodone group. Seventeen patients were excluded due to protocol violations. ${ }^{25}$

\section{Nonopioid agents}

Nonopioid agents are often used to manage neuropathic pain in a palliative care context, either alone or in conjunction with opioids, and they exert their effects through a variety of mechanisms. Antidepressants frequently prescribed include tricyclic antidepressants (nortriptyline, amitriptyline), selective serotonin reuptake inhibitors (paroxetine, fluoxetine), and selective serotonin-norepinephrine reuptake inhibitors (venlafaxine, duloxetine). They are postulated to provide pain relief by preventing the reuptake of biogenic amines, such as norepinephrine and serotonin, and by affecting agonist activity on $\alpha-2$ adrenoceptors. ${ }^{9}$ Analgesic effect is thought to be related to enhancement of descending inhibitory pathways in the central nervous system. ${ }^{4}$ Recently, a Cochrane review of 50 randomized trials concluded that tricyclic antidepressants are effective in treating neuropathic pain, but there is limited evidence to demonstrate the effectiveness of the selective serotonin reuptake inhibitors. ${ }^{26}$

Anticonvulsants such as gabapentin, pregabalin, lamotrigine, levetiracetam, and oxacarbazepine are thought to produce analgesia through modulation of central sensitization by inhibiting calcium flux through N-type channels. ${ }^{4}$ Ketamine, a dissociative anesthetic, and dextromethorphan, a cough suppressant, modulate central sensitization by effects on N-methyl-D-aspartate (NMDA) receptors.?

Lidocaine, a local anesthetic, can modulate peripheral sensitization by reversibly blocking and inactivating sodium channels ${ }^{4}$ and may be used topically or parenterally. ${ }^{27}$ Capsaicin modulates peripheral sensitization by depleting Substance P, in effect destroying a subset of small primary afferent fibers. ${ }^{4,28}$
Table 1. Proposed methadone-to-morphine conversion ratios

\begin{tabular}{|c|c|}
\hline Model & $\begin{array}{l}\text { Conversion ratio of morphine } \\
\text { to methadone }\end{array}$ \\
\hline Edmonton 38,40 & $10: 1$ to $11: 1$ \\
\hline Ripamonti $^{41}$ & $\begin{array}{l}\text { 4:1 if morphine } 30 \text { to } 90 \mathrm{mg} / \mathrm{d} \\
6: 1 \text { if morphine } 90 \text { to } 300 \mathrm{mg} / \mathrm{d} \\
8: 1 \text { if morphine }>300 \mathrm{mg} / \mathrm{d}\end{array}$ \\
\hline Soares ${ }^{32}$ & $\begin{array}{l}5: 1 \text { if morphine }<100 \mathrm{mg} / \mathrm{d} \\
10: 1 \text { if morphine } 100 \text { to } 300 \mathrm{mg} / \mathrm{d} \\
12: 1 \text { if morphine }>300 \mathrm{mg} / \mathrm{d}\end{array}$ \\
\hline $\begin{array}{l}\text { United Kingdom } \\
\text { model }^{37}\end{array}$ & $\begin{array}{l}10: 1 \text { if morphine }<300 \mathrm{mg} / \mathrm{d} \\
\text { If morphine }>300 \mathrm{mg} / \mathrm{d} \text { then } 30 \mathrm{mg} \\
\text { methadone }\end{array}$ \\
\hline
\end{tabular}

Many of these nonopioid agents have considerable side effects; antidepressants can cause anticholinergic side effects, and anticonvulsants can cause somnolence, dizziness, and blood and electrolyte abnormalities. Despite their side-effect profiles, these agents are considered to be first-line adjuvant analgesics for cancer-related neuropathic pain. ${ }^{3}$

\section{METHADONE}

\section{Properties}

Overactivation of NMDA receptors, a subtype of glutaminergic receptor, appears to be a common denominator in neuropathic pain. ${ }^{29,30}$ In addition to arbitrating typical inflammatory and ischemic pain through its affinity for $\delta$ and $\mu$ receptors in the central nervous system, ${ }^{31}$ methadone also noncompetitively inhibits the NMDA receptor, hence, purportedly, its effectiveness in ameliorating neuropathic pain. 32,33

While the NMDA-receptor-antagonist property of methadone makes it appealing as an agent in treating neuropathic pain, issues such as equianalgesic dosing are difficult to standardize and are a subject of debate in the literature. Recommendations have varied in regard to the morphine-to-methadone ratio's conversion from 4:1 to 14:1..$^{30,32,34-41}$ (See Table 1 for an example of some conversion ratios.) Some of the uncertainty can be explained by wide interpatient variability and bioavailability. The role of the NMDA receptor is also a factor in the changing ratio as the methadone dosage increases. ${ }^{42}$ Although authors differ on the exact equianalgesic dose, most agree that dosing varies according to dose range. ${ }^{34,39,43}$ Our experience with the Ripamonti protocol has been favorable.

Methadone has characteristics similar to those of other opioids, including side effects of nausea, constipation, 
Table 2. Substantiated pharmacokinetic interactions between methadone and other commonly used agents ${ }^{42,45}$

\begin{tabular}{|c|c|c|c|c|}
\hline Drug & Effect on methadone & Effect of methadone on drug & $\begin{array}{c}\text { Onset of } \\
\text { effect }\end{array}$ & $\begin{array}{l}\text { Mechanism } \\
\text { interaction }\end{array}$ \\
\hline Didanosine & none & $\downarrow$ plasma conc 60 percent & rapid & $\downarrow$ bioavailability \\
\hline Efavirenz & $\downarrow$ plasma conc & none & delayed & 3A4 inhibition \\
\hline Fluconazole & $\uparrow$ plasma conc 35 percent & none & unknown & 3A4 inhibition \\
\hline Fluvoxamine & $\uparrow$ plasma conc & none & delayed & 3A4 inhibition \\
\hline Nelfinavir & $\downarrow$ plasma conc 50 percent & none & delayed & 3A4 inhibition \\
\hline Nevirapine & $\downarrow$ plasma conc 50 percent & none & delayed & 3A4 inhibition \\
\hline Phenytoin & $\downarrow$ plasma conc 50 percent & none & delayed & 3A4 inhibition \\
\hline Rifampin & $\downarrow$ plasma conc 33 to 55 percent & none & delayed & 3A4 inhibition \\
\hline Risperidone & $\downarrow$ plasma conc & none & rapid & unknown \\
\hline Ritonavir & $\downarrow$ plasma conc 36 percent & none & delayed & 3A4 inhibition \\
\hline St. John's Wort & $\downarrow$ plasma conc 50 percent & none & delayed & 3A4 inhibition \\
\hline Voriconazole & $\uparrow$ plasma conc 35 percent & none & unknown & 3A4 inhibition \\
\hline Zidovudine & none & $\uparrow$ plasma conc 40 to 100 percent & delayed & unknown \\
\hline
\end{tabular}

headache, somnolence, euphoria, and respiratory depression. ${ }^{44}$ One property unique to methadone among the opioids is its variable half-life, estimated to be between 8.5 and 47 hours, which may result in respiratory depression if the drug is titrated up too rapidly. ${ }^{42}$ It may take three to 10 days to reach a steady state.

Major drug interactions are mostly secondary to the induction of CYP3A4-mediated methadone metabolism, and possibly protein-binding displacement. Problems with these drugs mainly occur when one of them is introduced while methadone is already at a stable dose. Communication between providers is essential. The CYP206 pathway is another that may be influenced by genetic differences. ${ }^{42,44}$ Table 2 lists important drug interactions.

Another unique methadone property is its potential to cause QTc-interval prolongation, especially in high doses. This may be partially due to variation in its metabolism. There are several published reports of Torsades de Pointes occurring during methadone treatment. ${ }^{30,45-47}$
Some authors suggest that no dose of methadone may be considered completely safe and that routine electrocardiograms should be considered, both initially and at various points during treatment. ${ }^{45,46}$ Although there is no consensus about EKG monitoring in the literature, it is prudent to be aware of the potential for QTc prolongation and to weigh risks and benefits and minimize other risk factors, such as electrolyte imbalance and drug interactions, that could increase circulating methadone levels. ${ }^{30,45,46}$

Table 3 summarizes pros and cons of methadone as compared to other opioids.

\section{Is methadone effective in the treatment of neuropathic pain?}

In a retrospective review of 50 consecutive patients with unrelieved nonmalignant neuropathic pain treated with oral methadone after being on various other agents (90 percent of whom were on chronic opioids), 26 


\begin{tabular}{|c|c|c|}
\hline \multicolumn{3}{|c|}{ Table 3. Pros and cons of methadone use $e^{42,44,45}$} \\
\hline Feature & Pro & Con \\
\hline Efficacy in cancer pain & $\begin{array}{l}\text { Comparable to other opioids, with } \\
\text { probable additional activity against } \\
\text { neuropathic pain }\end{array}$ & \\
\hline Neuropathic pain specific & Yes; NMDA receptor activity & \\
\hline Onset of action & 30 to 60 minutes $^{1}$ & \\
\hline Elimination half-life & Long & Long and variable \\
\hline Oral bioavailability & Excellent (can be variable) & \\
\hline Active metabolites & Few, less potential for myoclonus & \\
\hline Metabolism & & 3A4 causes interactions with other drugs ${ }^{3}$ \\
\hline Distribution & Lipophilic & \\
\hline Excretion & Feces & \\
\hline Routes of administration & Oral, IV, SQ, intraspinal, rectal & \\
\hline Variety of formulations & Multiple: liquid, tablet, parenteral & \\
\hline Titration & & $\begin{array}{l}\text { Slower than most other opioids; steady state } \\
\text { at three to } 10 \text { days }\end{array}$ \\
\hline Side effects compared to other opioids & Less potential for myoclonus & \\
\hline Cardiac effects & & $\begin{array}{l}\text { Prolonged QT, reported cases of Torsades } \\
\text { de Pointes }{ }^{2}\end{array}$ \\
\hline Equianalgesic dose calculations & & No consensus; varies with dose range \\
\hline Social stigma & & $\begin{array}{l}\text { Used in heroin addiction treatment, could } \\
\text { be negative }\end{array}$ \\
\hline Cost & Inexpensive & \\
\hline
\end{tabular}

reported some relief with oral methadone after 13.9 months of follow-up. The mean maximal opioid dose prior to switching to methadone was $384 \pm 64.6 \mathrm{mg} / \mathrm{d}$ (expressed as oral morphine equivalents). Twenty-four patients reported failure on the methadone, either due to intolerable side effects of nausea and vomiting (11), drowsiness (six), and constipation (two), or failure to respond to incremental dosing of the methadone (four). 5,48

Another study that supports methadone's effectiveness in managing neuropathic pain is a double-blinded, randomized, controlled crossover trial for nonmalignant neuropathic pain involving 18 patients with a diverse range of chronic neuropathic pain syndromes. As compared with placebo, methadone resulted in statistically significant improvements in patient ratings of maximum pain intensity, average pain intensity, and pain relief. The analgesic effects extended over 48 hours. Interpatient analysis showed that the analgesic effects were not restricted to any particular type of neuropathic pain. Patient compliance was high throughout the trial. This was the first double-blind, randomized, controlled trial to demonstrate that methadone has an analgesic effect. ${ }^{35}$

Gagnon ${ }^{49}$ reported a study of 18 cancer and noncancer patients with neuropathic pain who received relatively low doses (median stable dose of $15 \mathrm{mg} / \mathrm{d}$ ) of methadone. Mechanical allodynia and paroxysmal pain were assessed clinically. Mean pretreatment pain scores of $7.7 \pm 1.5 \mathrm{~cm}$ dropped significantly to $1.4 \pm 1.7 \mathrm{~cm}$ on a stable dose of methadone $(\mathrm{p}<0.0001)$. Nine of 13 patients (70 percent) experienced complete resolution of mechanical allodynia, and all eight patients with shooting pain reported a complete response. 
Another report describing 13 patients on methadone for neuropathic pain refractory to other opioids suggested that methadone was effective. Nine of the patients reported that methadone relieved their pain by 43 percent on average, improved quality of life by 47 percent, and improved sleep by 30 percent, as compared to before initiation of methadone..$^{50}$ The same authors published a case report of a 50-year-old burn victim with chronic neuropathic pain refractory to morphine, amitriptylline, and gabapentin. The patient was started on oral methadone, leading to a reduction in his neuropathic pain score from an 8 to a 4.5 on average. After 10 months on methadone, his pain score remained stable. The conclusion of this case report and others was that controlled studies are needed to better define the benefit of methadone in neuropathic pain. ${ }^{51}$

\section{Is methadone superior to other opioids for treating neuropathic pain?}

No human studies have been reported comparing methadone to other opioids for neuropathic pain, but two preclinical animal studies examining this question have been reported. One study examined development of tolerance to chronically administered methadone and morphine in a rat model of neuropathic pain after ischemic nerve injury. In drug-naïve neuropathic rats, systemically administered morphine or methadone similarly and dose-dependently alleviated mechanical allodynia. Tolerance to the antihyperalgesic effect of equally effective doses of morphine or methadone developed; however, the rate of tolerance development was significantly slower for methadone in comparison to morphine. Chronic morphine treatment for 14 days induced almost complete loss of the antiallodynic effect of morphine, whereas methadone still had partial effect after 21 days of chronic treatment. Partial cross-tolerance was observed between morphine and methadone. It is suggested that the delayed development of tolerance to methadone in neuropathic rats may be related to the higher intrinsic activity of methadone compared to morphine, as well as the NMDA-receptor-blocking property of methadone. The latter may also contribute to preservation of $\mu$-opioid antinociception following chronic methadone treatment. ${ }^{52}$

Morphine, methadone, and codeine were examined in rat models of peripheral and central neuropathic pain. In the spared nerve injury and chronic constriction injury models of peripheral neuropathic pain, both morphine and methadone attenuated mechanical allodynia, mechanical hyperalgesia, and cold allodynia, but codeine alleviated mechanical hypersensitivity only minimally, if at all. When administered to rats with spinal cord injury, morphine and methadone robustly attenuated mechanical and cold allodynia for at least two hours following injection $(\mathrm{p}<0.05)$. Codeine also attenuated mechanical and cold allodynia in this model for at least three hours after injection. Interestingly, the therapeutic window (based on antiallodynia vs. ataxia) obtained for codeine was vastly superior to that obtained with morphine or methadone. ${ }^{53}$

\section{Is methadone superior to other opioids in the treatment of cancer pain?}

NMDA-receptor activation appears to have influence in neuropathic pain as well as inflammatory and ischemic pain. The use of an opioid such as methadone, which inhibits NMDA, may improve pain control by also attenuating development to tolerance. Another theoretical advantage the addition of NMDA antagonism may confer is incomplete cross-tolerance with the potential to control pain that is no longer responsive to $\mu$-receptor-only agonists. $^{33}$

The 2004 Cochrane review of methadone for cancer pain looked at eight randomized, controlled trials of methadone versus active placebo (using widely varying agents). Unfortunately, the active placebo drugs, starting doses, titration regimens, and pain scales were markedly dissimilar and thus difficult to compare. However, the reviewers concluded that overall, methadone was comparable to morphine in both analgesic-effect and sideeffect profiles. The Cochrane reviewers also concluded that there was not enough trial evidence to support the proposal that methadone has a particular role in treating malignant neuropathic pain. ${ }^{10}$

In 2004, a randomized, double-blind study of 103 patients with cancer pain of various etiologies was conducted, in which the patients were randomly assigned to receive either oral methadone or morphine. The rates of patient-reported pain improvement and global benefit were nearly identical..$^{54}$ No further comparative studies have been performed since that time.

\section{Is methadone superior to other opioids in treating cancer-related neuropathic pain?}

Given that methadone is not only an opioid agonist but an inhibitor of the NMDA receptor, it has been postulated that methadone may be especially useful in palliating cancer-related neuropathic pain. ${ }^{48}$ Several small studies point to the effectiveness of methadone in the treatment of both neuropathic pain and cancer pain. But is methadone a superior analgesic for cancer-related neuropathic pain? There are no reported studies to answer this question, but methadone is clearly becoming more popular as an important opioid in many clinical situations. Cleary, ${ }^{36}$ in a bulletin of the American Academy of Hospice and Palliative Medicine, reflected on the growing use of methadone, especially in the pain and palliative care communities, as a "renaissance." 


\section{CONCLUSION}

Methadone has many appealing qualities: it is inexpensive, highly lipophilic, and bioavailable, allowing for oral (in tablet and solution), rectal, intravenous, subcutaneous, epidural, and intrathecal routes of administration. ${ }^{30,33,34}$ Unlike other long-acting opioid formulations, it can be divided. It is currently the only long-acting opioid in liquid form. It has no active metabolites, dramatically decreasing the potential for myoclonus. ${ }^{33}$ Although variable pharmacokinetics and somewhat complex conversions present a challenge, it has shown tremendous promise for the treatment of cancer-related neuropathic pain.

Overcoming the stigma associated with methadone's use in heroin addiction presents a second challenge, and it is imperative that healthcare providers be educated about this potentially important and effective agent in the management of such a difficult, compelling, and significant clinical problem as cancer pain.

Further comparative studies are needed to establish the efficacy of this important analgesic. For example, a double-blinded, randomized, crossover trial comparing morphine to methadone could be performed in cancer patients with chemotherapy-induced neuropathic pain syndromes. Pain relief, side-effect profiles, necessity of breakthrough medications, and costs of the treatment arms could be examined.

Rosemarie Mannino, MD, Fellow, Division of Hematology/ Oncology and Palliative Medicine, Massey Cancer Center, Virginia Commonwealth University School of Medicine, Richmond, Virginia.

Patrick Coyne, MSN, APRN, Clinical Director, Thomas Palliative Care Services, Massey Cancer Center, Virginia Commonwealth University Health Systems, Richmond, Virginia.

Craig Swainey, MD, Fellow, Division of Hematology/ Oncology and Palliative Medicine, Massey Cancer Center, Virginia Commonwealth University School of Medicine, Richmond, Virginia.

Lea Ann Hansen, PharmD, Associate Professor, Virginia Commonwealth University School of Pharmacy, Richmond, Virginia.

Laurie Lyckholm, MD, Associate Professor, Hematology/ Oncology and Palliative Medicine, Massey Cancer Center, Virginia Commonwealth University School of Medicine, Richmond, Virginia.

\section{REFERENCES}

1. Du Pen SL, Du Pen A, Polissar N, et al.: Implementing guidelines for cancer pain management: Result of a randomized controlled clinical trial. J Clin Oncol. 1999; 17(1): 361-370.

2. Miaskowski C, Cleary J, Burney R, et al.: Guidelines for the Management of Cancer Pain in Adults and Children. Glenville: American Pain Society, 2005.

3. McDonald A, Portenoy R: How to use antidepressants and anticonvulsants as adjuvant analgesics in the treatment of neuropathic cancer pain. J Support Oncol. 2006; 4(1): 43-52. 4. US Department of Health and Human Services: Breakthroughs and challenges in the management of common chronic pain conditions: A focus on neuropathic pain. Clinical Courier. 2005; 23(23): 3-10.

5. Caraceni A, Portenoy RK: An international survey of cancer pain characteristics and syndromes. IASP Task Force on Cancer Pain. International Association for the Study of Pain. Pain. 1999; 82(3): 263-274.

6. Boureau F, Doubrere JF, Luu M: Study of verbal description in neuropathic pain. Pain. 1990; 42(2): 145-152.

7. Wilkie DJ, Huang HY, Reilly N, et al.: Nociceptive and neuropathic pain in patients with lung cancer: A comparison of pain quality descriptors. J Pain Symptom Manage. 2001; 22(5): 899-910.

8. Portenoy RK, Foley KM, Inturissi CE: The nature of opioid responsiveness and its implications for neuropathic pain: New hypotheses derived from studies of opioid infusions. Pain. 1990: 43(3): 273.

9. Doyle D, Hanks G, McDonald N, et al.: Difficult pain problems: An integrated approach. Oxford Textbook of Palliative Medicine, $3^{\text {rd }}$ edition. Oxford: Oxford University Press, 2004.

10. Nicholson AB: Methadone for cancer pain. Cochrane Database Syst Rev. 2004; 2: CD003971.

11. Elliott K, Foley KM: Neurologic pain syndromes in patients with cancer. Crit Care Clin. 1990; 6(2): 393-420.

12. Pierce SM, Recht A, Lingos TI, et al.: Long-term radiation complications following conservative surgery (CS) and radiation therapy (RT) in patients with early stage breast cancer. Int J Radiat Oncol Biol Phys. 1992; 23(5): 915-923.

13. Perttunen K, Tasmuth T, Kalso E: Chronic pain after thoracic surgery: A follow-up study. Acta Anaesthesiol Scand. 1999; 43(5): 563-567.

14. Macdonald L, Bruce L, Scott L, et al.: Long-term follow-up of breast cancer survivors with post-mastectomy pain syndrome. Br I Cancer. 2005; 92(2): 225-230.

15. Ben Abraham R, Marouani N, Kollender Y, et al.: Dextromethorphan for phantom pain attenuation in cancer amputees: A double-blind crossover trial involving three patients. Clin J Pain. 2002; 18(5): 282-285.

16. Cherny N: Cancer pain: Principles of assessment and syndromes. In Berger A, Portenoy R, Weissman D (eds.): Principles and Practice of Supportive Oncology. Philadelphia: Lippincott, Williams, and Wilkins, 2002.

17. Bach S, Noreng MF, Tellden NU: Phantom limb pain in amputees during the first 12 months following limb amputation, after pre operative lumbar epidural blockade. Pain. 1988; 33(3): 297-301.

18. Katz J: Prevention of phantom limb pain by regional anaesthesia. Lancet. 1997; 349(9051): 519-520.

19. Windebank A: Chemotherapeutic neuropathy. Curr Opin Neurol. 1999; 12(5): 565-571.

20. Quastoff S, Hartung HP: Chemotherapy-induced peripheral neuropathy. J Neurol. 2002; 249(1): 9-17.

21. Verstappen CP, Heimans JJ, Hoekman K, et al.: Neurotoxic complications of chemotherapy in patients with cancer. Drugs. 2003; 63(15): 1549-1563.

22. Davis MP, Walsh D, Lagman R, et al.: Controversies in pharmacotherapy of pain management. Lancet Oncol. 2005; 6(9): 696-704.

23. Watson CPN: Efficacy of oxycodone in neuropathic pain: A randomized trial in postherpetic neuralgia. Neurology. 1998; 50(6): 1837-1841.

24. Watson CPN, Moulin D, Watt-Watson J, et al.: Controlledrelease oxycodone relieves neuropathic pain: A randomized controlled trial in painful diabetic neuropathy. Pain. 2003; 105(1-2): 71-78. 
25. Gimbel J, Richards P, Portenoy R: Controlled-release oxycodone for pain in diabetic neuropathy: A randomized controlled trial. Neurology. 2003; 60(6): 927-934.

26. Saarto T, Wiffen PJ: Antidepressants for neuropathic pain. Cochrane Database Syst Rev. 2005; 3: CD005454.

27. Ferrini R, Paice J: How to initiate and monitor infusional lidocaine for severe and/or neuropathic pain. J Support Oncol. 2004; 2(1): 90-94.

28. DRUGDEX System (Internet database): Capsaicin. Thomson Micromedex. Available at www.micromedex.com/products/ drugdex. Accessed May 8, 2006.

29. Ebert B, Thorkildsen C, Andersen S, et al.: Opioid analgesics as noncompetitive N-methyl-D-aspartate (NMDA) antagonists. Biochem Pharmacol. 1998; 56(5): 556-559.

30. Brown R, Kraus C, Fleming M, et al.: Methadone: Applied pharmacology and use as adjunctive treatment in chronic pain. Postgrad Med J. 2004; 80(949): 654-659.

31. Lacy CF, Armstrong L, Goldman M, et al.: Drug Information Handbook, $8^{t h}$ edition. Hudson: Lexi-Comp, 2000.

32. Soares L: Methadone for cancer pain: What have we learned from clinical studies? Am J Hosp Palliat Care. 2005; 22(3): 223-226. 33. Fitzgibbon D: Cancer pain management. In Loeser J (ed.): Bonica's Management of Pain, $3^{\text {rd }}$ edition. Philadelphia: Lippincott, Williams, and Wilkins, 2001.

34. Zimmerman C, Seccareccia D, Booth C, et al.: Rotation to methadone after opioid dose escalation: How should individualization of dosing occur? J Pain Palliat Care Pharmacother. 2005; 19(2): 25-31.

35. Morley JS, Bridson J, Nash T, et al.: Low dose methadone has an analgesic effect in neuropathic pain: A double blinded randomized controlled crossover trial. Palliat Med. 2003; 17(7): 576-587.

36. Cleary JF, Foley D: Methadone: The ideal long-acting opioid? AAHPM Bulletin. 2002; Winter: 6-7.

37. Morley JS, Makin MK: Comments on Ripamonti et al. Pain. 1997; 73(1): 114-115.

38. Bruera E, Pereira J, Watanabe S, et al.: Opioid rotation in patients with cancer pain. A retrospective comparison of dose ratios between methadone, hydromorphone, and morphine. Cancer. 1996; 78(4): 852-857.

39. Mercadante S, Casuccio A, Fulfaro F, et al.: Switching from morphine to methadone to improve analgesia and tolerability in cancer patients: A prospective study. J Clin Onc. 2001; 19(11): 2898-2904.

40. Lawlor PG, Turner KS, Hanson J, et al.: Dose ratio between morphine and methadone in patients with cancer pain: A retrospective study. Cancer. 1998; 82(6): 1167-1173.

41. Ripamonti C, Groff L, Brunelli C, et al.: Switching from morphine to oral methadone in treating cancer pain: What is the equianalgesic dose ratio? J Clin Oncol. 1998; 16(10): 3216-3221. 42. Ferrari A, Coccia CPR, Bertolini A, et al.: Methadonemetabolism, pharmacokinetics and interactions. Pharmacol Res. 2004; 50(6): 551-559.

43. Bruera E: Methadone: An essential analgesic to manage pain in cancer. Cancer Pain Release. 2005; 18(1): 1-3.

44. DRUGDEX System (Internet database). Methadone. Thomson Micromedex. Available at www.micromedex.com/ products/drugdex. Accessed May 8, 2006.

45. Hernandez AM, Fernandez FA, Maiz AA, et al.: Torsades de Pointes during methadone treatment. Rev Esp Cardiol. 2005: 58: 1230-1232.

46. Ower K, Morley-Forster P, Moulin D: Fluctuating QTc interval in an asymptomatic patient treated with methadone for chronic pain. Journal of Opioid Management. 2005; 1(2): 73-76. 47. Porter BO, Coyne PJ, Smith WR: Methadone-related Torsades de Pointes in a sickle cell patient treated for chronic pain. Am J Hematol. 2005; 78(4): 316-317.

48. Moulin D, Palma D, Watling C, et al.: Methadone in the management of intractable neuropathic non cancer pain. Can J Neuro Sci. 2005; 32(3): 341-343.

49. Gagnon B, Abdulaziz A, Schrier G: Methadone in the treatment of neuropathic pain. Pain Res Manage. 2003; 8(3): 149154.

50. Altier N, Dion D, Boulanger A, et al.: Management of neuropathic pain with methadone: A review of 13 cases. Clin J Pain. 2005; 21(4): 364-369.

51. Altier N, Dion D, Boulanger A, et al.: Successful use of methadone in the treatment of chronic neuropathic pain arising from burn injuries: A case study. Burns. 2001; 27(7): 771-775.

52. Bulka A, Plesan A, Xu XJ, et al.: Reduced tolerance to the anti-hyperalgesic effect of methadone in comparison to morphine in a rat model of mononeuropathy. Pain. 2002; 95(1-2): 103-109.

53. Erichsen HK, Hao JX, Xu XJ, et al.: Comparative actions of the opioid analgesics morphine, methadone and codeine in rat models of peripheral and central neuropathic pain. Pain. 2005; 116(3): 37-58.

54. Bruera E, Palmer JL, Bosnjak S, et al.: Methadone versus morphine as a first-line strong opioid for cancer pain: A randomized, double-blind study. JClin Oncol. 2004; 22(1): 185-192.

\section{CORRECTION}

Two typographical errors appeared in "The ACTION study: A randomized, open-label, multicenter trial comparing once-a-day extended-release sulfate capsules (AVINZA ${ }^{\circledR}$ ) to twice-a-day controlled-release oxycodone hydrochloride tablets (OxyContin ${ }^{\circledR}$ ) for the treatment of chronic, moderate to severe low back pain" (Rauck et al. 2006; 2(3): 155-156). Line 8 of paragraph 4 on p. 157 should read "scores consistently $\leq 4$," not "scores consistently $=4$." In Table 4 on p. 164, the incidence of nausea associated with O-ER in the AST population should be 54 percent, not 564 percent. The Journal apologizes for these errors. 